\title{
BMJ Open Conceptualising paediatric health disparities: a metanarrative systematic review and unified conceptual framework
}

\author{
Jennifer L Ridgeway, ${ }^{1}$ Zhen Wang, ${ }^{2}$ Lila J Finney Rutten, ${ }^{2}$ Michelle van Ryn, ${ }^{4}$ \\ Joan M Griffin, ${ }^{2}$ M Hassan Murad, ${ }^{2}$ Gladys B Asiedu, ${ }^{1}$ Jason S Egginton, ${ }^{1}$ \\ Timothy $\mathrm{J} \mathrm{Beebe}^{3}$
}

To cite: Ridgeway JL, Wang Z, Finney Rutten LJ, et al. Conceptualising paediatric health disparities: a metanarrative systematic review and unified conceptual framework. BMJ Open 2017;7:e015456. doi:10.1136/ bmjopen-2016-015456

- Prepublication history and additional material are available. To view these files please visit the journal online (http://dx.doi org/10.1136/bmjopen-2016015456).

Received 5 December 2016 Revised 3 May 2017 Accepted 22 May 2017

\section{CrossMark}

${ }^{1}$ Mayo Clinic Robert D. and Patricia E. Kern Center for the Science of Health Care Delivery, Mayo Clinic, Rochester, Minnesota, USA

${ }^{2}$ Department of Health Sciences Research, Mayo Clinic Robert D. and Patricia E. Kern Center for the Science of Health Care Delivery, Mayo Clinic, Rochester, Minnesota, USA

${ }^{3}$ Division of Health Policy and Management, School of Public Health, University of Minnesota, Minneapolis, Minnesota, USA

${ }^{4}$ Department of Health Sciences Research, Mayo Clinic, Rochester, Minnesota, USA

Correspondence to Dr Timothy J Beebe; beebe026@umn.edu

\section{ABSTRACT}

Objective There exists a paucity of work in the development and testing of theoretical models specific to childhood health disparities even though they have been linked to the prevalence of adult health disparities including high rates of chronic disease. We conducted a systematic review and thematic analysis of existing models of health disparities specific to children to inform development of a unified conceptual framework.

Methods We systematically reviewed articles reporting theoretical or explanatory models of disparities on a range of outcomes related to child health. We searched Ovid Medline In-Process \& Other Non-Indexed Citations, Ovid MEDLINE, Ovid Embase, Ovid Cochrane Central Register of Controlled Trials, Ovid Cochrane Database of Systematic Reviews, and Scopus (database inception to 9 July 2015). A metanarrative approach guided the analysis process. Results A total of 48 studies presenting 48 models were included. This systematic review found multiple models but no consensus on one approach. However, we did discover a fair amount of overlap, such that the 48 models reviewed converged into the unified conceptual framework. The majority of models included factors in three domains: individual characteristics and behaviours (88\%), healthcare providers and systems (63\%), and environment/community $(56 \%)$. . Only $38 \%$ of models included factors in the health and public policies domain.

Conclusions A disease-agnostic unified conceptual framework may inform integration of existing knowledge of child health disparities and guide future research. This multilevel framework can focus attention among clinical, basic and social science research on the relationships between policy, social factors, health systems and the physical environment that impact children's health outcomes.

Adult health disparities across sex, race and ethnicity, socioeconomic status (SES), disability status and other social characteristics have been well documented in the USA, ${ }^{12}$ and the geographic and temporal trends of these health disparities have persisted over time. $^{3-7}$ Research on child health has also
Strengths and limitations of this study:

- This systematic review was able to identify and synthesise a large number of models with varying constituent parts.

- The search was not restricted by underlying disease, health status and racial or ethnic group and thus the framework can be applied in many types of research in child health disparities.

- This review is limited to models in developed countries.

- Current data limitations may hamper the ability to test the proposed framework empirically, but the framework can guide future work including data collection.

documented a persistence of disparities, ${ }^{8}$ with unequal care or outcomes by race and SES for a range of conditions including asthma ${ }^{9}$ and cancer, ${ }^{10}{ }^{11}$ and unequal access to treatment. ${ }^{12}{ }^{13}$ Despite a growing evidence base, disproportionately less attention has been given to health disparities in children compared with adults. ${ }^{14}$

Eliminating health disparities is challenging because inequities are driven by multilevel influences including legislative policies, social factors, healthcare availability and access, individual behaviour, biology and genetics. ${ }^{6}{ }^{15}$ Multilevel interventions, therefore, are required to address social, environmental and organisational factors, as well as individual behaviour. ${ }^{16-18}$ For example, those in lower income strata are exposed to different environmental hazards and social stressors than more advantaged population groups, which may in turn have consequences for health. ${ }^{19-21}$ While associations between race, ethnicity, SES and health outcomes have been identified, the underlying mechanism and causal links are still debated. ${ }^{22}$ 
Theoretical models have been developed to guide health disparities research. ${ }^{23}$ Some include environmental or social factors, which may be present at birth or could impact health over the life course. ${ }^{24}$ Although a life course perspective is critical to understanding child health and the transition from child to adult health, the focus of these models largely remains on outcomes in adulthood. Furthermore, many of the contributors to disparities in child health overlap with and are partially mediated through their impact on the health and well-being of the adults who care for them, making the theoretical and explanatory models developed to explain adult health disparities inadequate for children. ${ }^{14}$ There are several characteristics that differentiate child health from adult health, as summarised in the five D's: developmental change, dependency on adults, differential epidemiology, demographic patterns and dollars. ${ }^{25}{ }^{26}$ Likewise, the development of models focused on child disparities is important because social and developmental forces of child disparities and the strategies to address them may differ from the adult population. The research to develop and refine conceptual frameworks for health disparities that are unique to child populations is just emerging. We aimed to systematically review existing models and identify commonalities that could inform development of a unified conceptual framework for assessing and analysing health disparities in children. While the number of studies on paediatric health disparities has been increasing, they continue to primarily describe existing inequities. ${ }^{27}$ Conceptual frameworks are needed to guide research on intervention development and testing, thus providing an avenue for eliminating disparities. They also provide a common language and set of definitions/concepts to move the science forward.

\section{METHODS}

We developed a study protocol at the beginning of the study (available from authors). The reporting of the manuscript follows the PRISMA (Preferred Reporting Items for Systematic Reviews and Meta-Analyses) statement. ${ }^{28}$

\section{Search strategy}

An experienced research librarian, along with the principal investigators, developed the search strategy (online supplementary appendix A). A comprehensive search of six databases (Ovid Medline In-Process \& Other Non-Indexed Citations, Ovid MEDLINE, Ovid Embase, Ovid Cochrane Central Register of Controlled Trials, Ovid Cochrane Database of Systematic Reviews, and Scopus) was conducted from each database's inception to 9 July 2015. Controlled vocabulary supplemented with keywords was used to search for theoretical or conceptual models of health and racial/ethnic disparities in children. Systematic reviews and meta-analyses were used to identify additional studies.

\section{Study selection}

Studies were included if they reported theoretical models (ie, proposed or derived from theory) or conceptual models (ie, presenting specific relationships between concepts or variables) of health disparities in children aged less than 18 years and were created for use in developed countries. We included studies of any design (randomised or non-randomised, observational, theoretical/conceptual) as long as they presented a new model or empirically tested an existing model. We excluded editorials, erratum, letters or notes. The search was not restricted by underlying disease, health status and racial or ethnic group. Studies published in languages other than English were excluded. Only the first published/ original study of a model was included.

For citations identified from MEDLINE, we adopted an advanced text-mining technique to improve the efficiency and reduce the workload of abstract screening. ${ }^{29}$ The text-mining technique employs three semantics-based relevant ranking metrics (keywords relevance, indexedterm relevance and topic relevance). A total score with a linear aggregation of three ranking metrics was generated to show relevance of each potential study. This method has been tested in multiple systematic reviews and shown to have good performance. ${ }^{29}$ The 500 highest ranking (most relevant) studies were selected to be screened for full text. A sample of 20 studies was selected to test the performance of the text-mining technique. Of the 20 studies, $18(90 \%)$ were included in the 500 studies, giving us confidence that the technique was valid. Two missing studies from the 20 studies were added to the 500 studies selected through text mining. Reviewers screened the 502 abstracts to identify those that met criteria, and then reviewed the full text. Each abstract and full text was screened independently by two reviewers, and a third reviewer resolved discrepancies. For citations identified from other databases, a traditional screening process was used: reviewers, working independently and in duplicate, screened the abstracts and then full texts, and a third reviewer resolved discrepancies.

\section{Data extraction}

A standardised extraction form was developed and tested using a sample of the included studies $(n=5)$. The following were extracted: authors' names, country of study or of lead author, objective of the development or use of the model in the study, population and disparity targeted, and components of the model.

\section{Methodological quality appraisal}

We did not find existing tools to evaluate the methodological quality of conceptual models; therefore, we developed our own criteria. Reviewers assessed whether the model was validated (yes/no/unclear/not applicable) and whether it was based on existing theory or was wholly empirical (theory/empirical/both/neither/ unclear). Based on this information, reviewers made a global rating of methodological quality as good, medium or low/unclear quality. Models based on empirical 
evidence or tested empirically were judged to have good methodological quality, while those based on theory alone were thought to have medium quality. Unclear or poorly reported descriptions of studies were labelled as unclear/low methodological quality.

\section{Analysis}

A metanarrative approach guided the analysis process. ${ }^{30}$ This approach has been evaluated and adopted in multiple studies. ${ }^{31} 32$ It includes six phases: planning, search, mapping, appraisal, synthesis and recommendations. The planning, search and appraisal phases for this study are described above in the Search strategy, Study selection, Data extraction and Methodological quality appraisal sections. The mapping phase included identification of elements in the research paradigm, in this case the study populations, the disparities addressed and the components of the presented models. The synthesis phase involved creating narrative accounts of the dimensions, linking concepts and seeking explanations for contradictory findings. The recommendations phase offers direction for practice, policy and further research. The aim in metanarrative synthesis was to identify domains that could serve as a unified conceptual framework for child health disparities research. This unified conceptual framework can provide an overarching structure (based on a synthesis of many different models' components) that informs empirical testing and enhances understanding of determinants of disparities that, in turn, can guide research and policymaking.

\section{RESULTS}

We identified 7477 citations through database searching (figure 1); 3115 abstracts were screened (502 MEDLINE and 2613 non-MEDLINE) and 210 met criteria for full-text assessment. Forty-eight of those citations met inclusion criteria and were included in the qualitative synthesis. Forty-eight different theoretical or conceptual models were presented, 41 of which were developed in North America (37 in the USA and 4 in Canada), 3 in Europe (Netherlands, Ireland and the UK) and 4 in other regions. Seventeen models were intended to address general health disparities, 5 oral health disparities, 5 racial/ethnic disparities and 21 other topics. Eleven models targeted the general paediatric population while 37 targeted specific paediatric populations.

Eighteen out of $48(37.5 \%)$ models were developed from empirical evidence while $19(39.6 \%)$ were developed from theory alone. Eighteen $(37.5 \%)$ of the models were empirically evaluated. The methodological quality was judged to be good in $10(20.8 \%)$, medium in 17 $(35.4 \%)$ and low/unclear in $21(43.8 \%)$ of the models. The detailed characteristics of the studies describing these models are provided as online supplementary appendix B.

\section{Components of the unified conceptual framework}

This systematic review found multiple models guiding the assessment of childhood health disparities. There was no consensus on one approach or validation of a unified

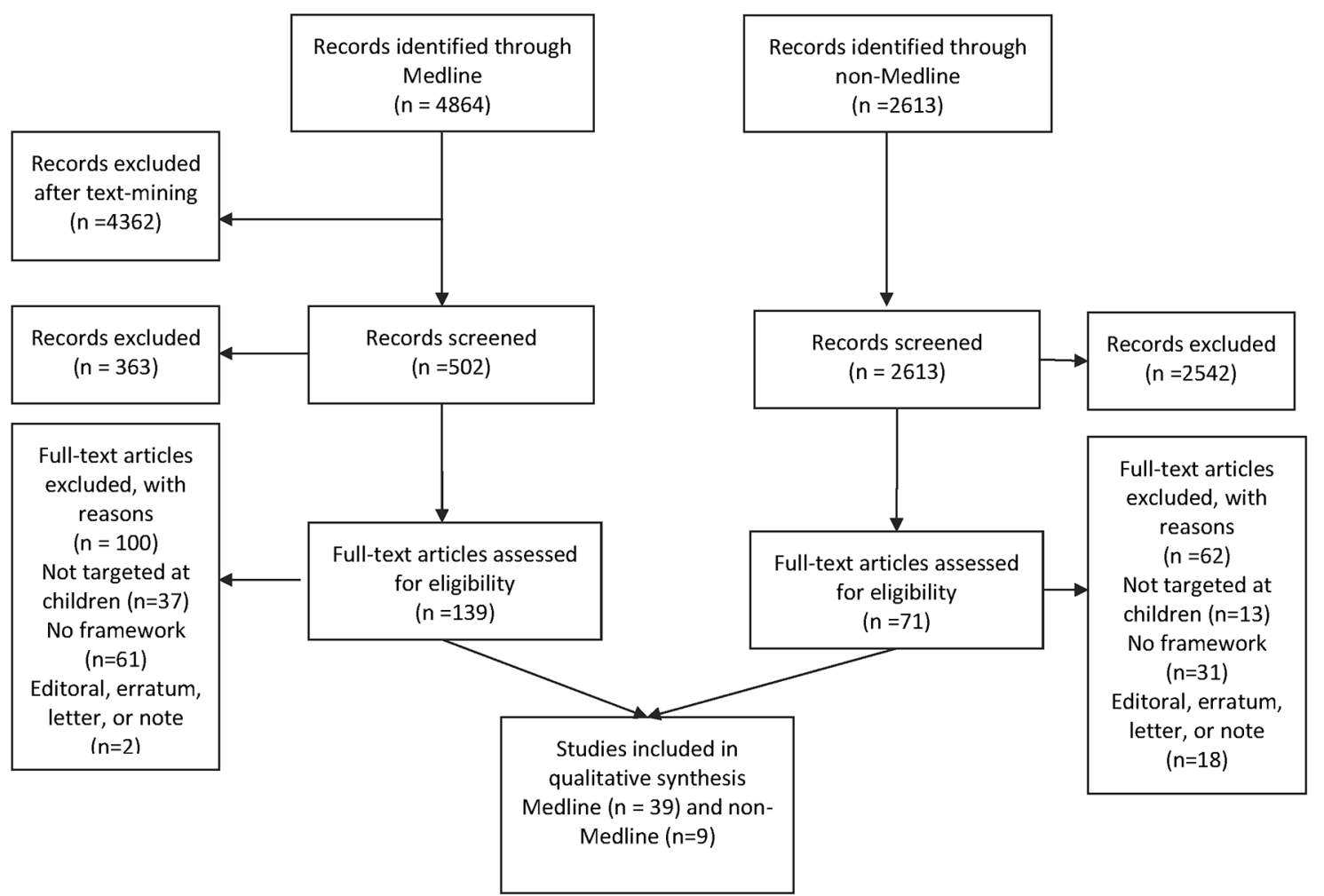

Figure 1 Process of study selection and screening using the PRISMA flow diagram. ${ }^{28}$ PRISMA, Preferred Reporting Items for Systematic Reviews and Meta-Analyses. 
model, but analysis using the metanarrative approach found convergence along four domains or levels of influence: individual characteristics and behaviours, healthcare providers and systems, environment/community, and health and public policies. We describe the levels below, along with themes representing the types of variables included in each level. These themes may guide future work to operationalise what we propose as a unified conceptual framework.

\section{Individual characteristics and behaviours}

The majority (42 or $88 \%$ ) of models in this review included factors consistent with individual characteristics and behaviours of the parent and/or child. The factors in this level can be summarised in three overlapping themes: sociodemographic factors; genetic, biological and psychological factors; and knowledge, attitudes and behaviours. The first theme, sociodemographic factors, extends beyond personal socioeconomic factors and includes issues such as race/ethnicity, immigration status, language and language acculturation, age, birth order, employment status (parent/guardian as well as child/ student) and gender. ${ }^{143-57}$ It also includes socioeconomic factors related to the family, including parents' support network, parental involvement in school or monitoring of peers, maternal hardship, household size and family structure. ${ }^{34} 35373841444548495558-62$

Models in the second theme, genetic, biological and psychological factors, represent a range of disparities. $^{36405763}$ Issues discussed within the genetics and biological theme ranged from associations between variants of the ADAM33 gene and asthma in Caucasian and Latino Americans and the presence of the Arg16 allele and asthma severity, ${ }^{36}$ to the factors involved in the pathogenesis of diseases and how they might vary by race and ethnicity. ${ }^{40}$ Psychological factors addressed in this theme include resilience, ${ }^{58}$ emotional, cognitive and social isolation, ${ }^{59}$ perceptions of and locus of control ${ }^{64}$ personality, ${ }^{14}$ stress, ${ }^{53}$ trauma $^{60}$ and developmental delays. ${ }^{65}$

The third theme focuses on relevant knowledge, attitudes and behaviours, especially those of parents. Knowledge included understanding of diseases or treatments and the healthcare system, as well as general understanding of the consequences of poor health, media use, and health literacy and numeracy. ${ }^{11} 1436434651526667$ Attitudes included perceptions of the affordability and acceptability of healthcare, belief in the value of preventive versus acute care, spirituality and religiosity, distrust of healthcare providers or systems, and cultural beliefs about health. ${ }^{364345485152646869}$ Parent behaviours were seen as heavily influenced by other levels of influence and included smoke exposure, bedtimes or mealtimes, safety practices like seat belt use, child-proofing of homes, and use of home remedies, illness management and adherence to treatment recommendations. Child behaviours were seen to be heavily influenced by both parental behaviour and other levels of influence and include diet, sleep, exercise, personal and dental hygiene, and alcohol, tobacco and other drug use. ${ }^{11} 1438414452535860-6370-72$

\section{Healthcare providers and systems}

Issues pertaining to the healthcare providers and systems level of influence were mentioned in $30(63 \%)$ of 48 models. Two overlapping themes emerged. First, access to healthcare included the supply/shortages of providers, affordability, health insurance coverage, having a usual source of care, access to specialty care, ancillary services (eg, translation services, patient health education, and so on), system fragmentation/integration, office hours, referral practices, hospice supply and managed care models. ${ }^{11} 143336373941455256586163-6567687072-76$ Second, quality of care included: lack of care coordination, diagnosis delays, gaps in the use of evidence-based medicine, delayed or foregone care, wait times; use of emergency care versus primary care, a variety of problems with the cultural competence/sensitivity, lack of diversity of the healthcare workforce, the presence of unintentional bias or stereotyping, language barriers, poor patient-provider communication and shared decision making, power and authority differentials, intimidation, prejudice, patient-provider race/ethnicity concordance, and physician workload or burnout. ${ }^{11} 1433$ 35-42 44-46 52 64-68 727475

\section{Environment/Community}

Twenty-seven of the identified models $(56 \%)$ included factors consistent with an environment/community level of influence. We found this level of influence to include three themes. First was the impact of social class or SES on child health disparities. As environmental factors, these speak to the opportunities available to children and their families. Examples included the detrimental impact of foreshortened economic opportunities, experiences of discrimination and potential for beneficial social connections. ${ }^{11} 1433$ 38-40 51 $576062-64667275$ Second were characteristics of the neighbourhood. These include crime rates, unemployment rates, school quality, public service availability, access to healthy stores, positive neighbourhood attributes (eg, sidewalks, play areas, recreation centres, libraries/bookmobiles), negative neighbourhood attributes (eg, higher concentrations of pollution-emitting buildings, litter, dilapidated housing, vandalism) and neighbourhood instability (eg, low home ownership). ${ }^{36-38} 40414351-5460-636569-7174$ Last was the relevance and importance of environmental exposures. Six of the models reviewed included such elements as indoor and outdoor allergens, pollution exposure, environmental stress and fluoridation in the water. ${ }^{36-38} 41616370$

\section{Health and public policies}

Eighteen $(38 \%)$ of the 48 models included health and public policies. Policy factors included those targeting the formation and activation of community health partnerships, ${ }^{77}$ the design of and access to health insurance, public sector nutritional programmes (eg, Special Supplemental Program for Women, Infants, and Children (WIC)), policies aimed at health behaviour (eg, soda and tobacco taxes), and employment, economic development 
or income policies. ${ }^{11} 33 \quad 36-38404850606164676870727378$ Some of these models noted the potential of public policies to reduce or increase health disparities by virtue of their ability to create access to programmes. The most commonly included factor was health insurance access/coverage. Public policies were also conceived of as having the potential to influence behaviour, for example, restricting the types of beverages that can be purchased using food programmes to change consumption patterns. ${ }^{61}$

\section{DISCUSSION}

The elimination of health disparities has been the focus of research and policymaking for decades. ${ }^{79-85}$ Despite this history, the research agenda for child health disparities is just emerging, and there exists a paucity of work in the development and testing of theoretical models specific to child health disparities, even though they have been linked to the prevalence of adult health disparities including high rates of chronic disease, ${ }^{22} 86$ and practitioners and advocates have called for addressing poverty and other factors in childhood that affect both child and subsequently adult health. ${ }^{878}$

While we did not find consensus with one approach, we did identify a fair amount of overlap of factors that can be organised into four domains. Functionally, the four levels of the proposed framework are consistent with the socioecological model and other ecological models that conceptualise a complex nested set of factors and relationships that impact health and health disparities (figure 2). ${ }^{89}$ The socioecological model focuses on understanding multiple and interactive personal and environmental factors that influence health outcomes, portrayed as levels of influence on individual human development. ${ }^{16179091}$ Influence is also applied by the larger health and social service systems, the environment or neighbourhood in which individuals live, and the greater cultural and political conditions. In fact, disparities in healthcare, educational and other systems play a critical role in resulting health disparities among children and their communities and families. ${ }^{53}$ This can be seen in the historical influence of health and education systems on child disparities in the American Indian and Alaska Native communities. ${ }^{92}$ In this framework, we portray the underlying role-explicitly or through more subtle channels-of health and public policies on the other domains of paediatric disparities, as well as the reciprocal influence of environment/community and individual characteristics and behaviours.

Among the papers reviewed, the model portrayed by Raphael and Beal $^{14}$ highlights how disparities models created for adult health, like that by Warnecke and colleagues, ${ }^{18}$ need to consider aspects specific to paediatric patients. Our study largely coincides with the Raphael and Beal model but its broader attention to conceptual models being used in a range of disparities_expanding beyond race and ethnicity to include studies of disparities based on sexual orientation or disability status-may demonstrate that similar constructs are salient to other areas of paediatric disparities research. Although the number of these

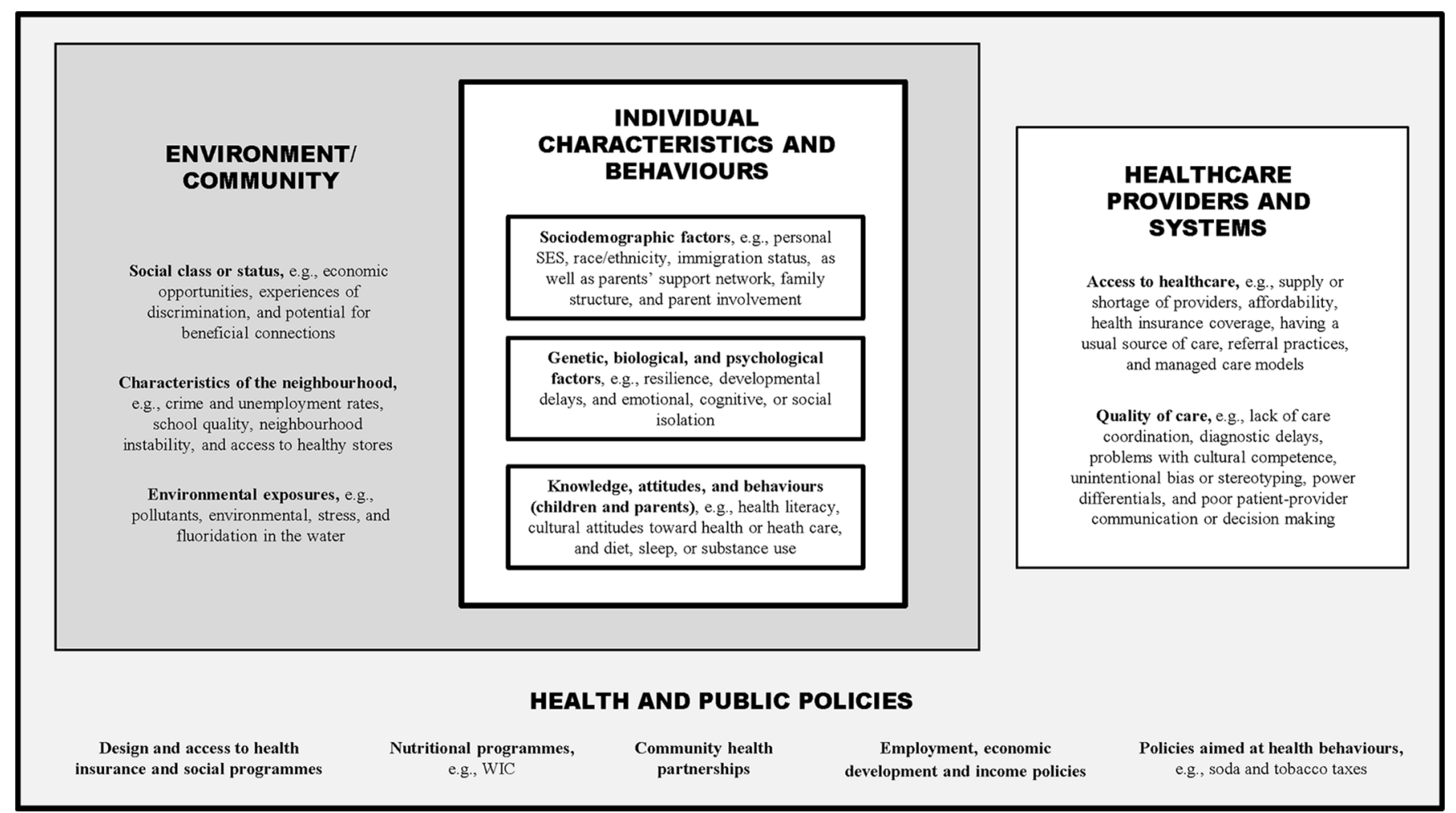

Figure 2 This unified conceptual framework presents a multilevel view of factors related to paediatric health disparities. SES, socioeconomic status; WIC, Special Supplemental Program for Women, Infants, and Children. 
studies in our review was small, future research should aim to assess how a paediatric disparities framework can be expanded to be more inclusive of factors relevant to other vulnerable paediatric populations.

It is notable that while disparities and socioecological models stress the importance of multiple interacting levels of influence, only 10 of the 48 models reviewed for this study included items in each of the four domains described herein. Furthermore, while 42 of the 48 models included constructs related to individual characteristics, only 27 included environmental or community characteristics. This is a critical issue for paediatrics disparity research and the potential to address disparities through intervention. Children spend their time in different ways and in different settings. For example, children in the USA spend an average of around 1200 hours in school each year ${ }^{93}$ with significant implications for health and health disparities. ${ }^{94}$ However, explication and understanding of the various features of school exposures (and protective factors) for child health disparities has been vastly underdeveloped as compared with the explication and understanding of the various features of occupational settings on adult health disparities. In addition, the kind, intensity and impact of psychosocial and environmental exposures may differ greatly for children as compared with adults, not least because of their impact on healthy child development. ${ }^{95} 96$ The environmental, developmental and social determinants of child and adolescent health-related behaviour are distinct in several respects from the environmental, developmental and social determinants of adult health-related behaviour. Resilience and protective factors need to be considered differently for children than adults; as one example, the way social networks and social ties (structure, features and functions) influence child health may differ greatly from the ways in which social networks and ties affect adult health. ${ }^{97}$ Inadequate conceptualisation of the determinants of child health and health disparities limits our ability to develop effective remedies.

Likewise, few models included items related to the healthcare provider and systems domain $(n=30)$ or the health and public policy domain $(n=18)$, although these factors have potential to exacerbate or intervene to eliminate health disparities. While the process of creating or modifying policies and addressing structural inequities in the healthcare system is difficult, these efforts are necessary to make a large-scale impact on health disparities and disrupt persistent patterns in inequities. Recent work in the field of paediatric bioethics highlights the role of healthcare providers in being attentive to what is already known about the social determinants of child health disparities. ${ }^{98}$

This review also found that research on child disparities includes constructs that are familiar in life course models, including the model proposed by the National Research Council and the Institute of Medicine.${ }^{99}$ Children's dependency on adults, their interactions with physical and social environments, and their capacity to develop resiliency are not static over their development, and there are critical time points for dynamic change, for example, birth, entrance to school and puberty. ${ }^{99}$ Our framework does not explicitly demonstrate a life course perspective but these findings point to the fact that there are many points across the life course where disparate conditions bifurcate what would otherwise be a healthy trajectory for children. This may contribute to future efforts at finding points of intersection between life course models, which posit a dynamic view of child health and the influence of many factors over time, and disparities models, which provide a platform for understanding population-level inequities in health.

There are limitations to this study. First, although the figure suggests nested relationships among the components, little effort in the extant literature has been directed at ascertaining how the components interact functionally (eg, interaction between genes and environment). Our analyses did point to potential constituent parts of the different components and ideas for how the four components might interact. For example, at the policy level of influence, alterations to medical insurance programmes for children that are aimed to contain costs may directly impact the access to and the quality of healthcare received by limiting the number of paediatricians willing to accept public pay clients. Moreover, an individual's genetic characteristics can interact with the environment. For example, autism may be triggered by a mother's exposure to environmental agents such as air pollution or pesticides while pregnant. ${ }^{100}$ These exposures, in turn, could cause or contribute to autism development. Two models, by Canino and colleagues ${ }^{36}$ and by Raphael and Beal, ${ }^{14}$ show promise in identifying how domains in the models interact. Nonetheless, more research that explicates the relationships between the components is needed.

Second, the search was limited to studies published in English due to feasibility. It is possible that models published in other languages may have different elements or offer different inferences. Likewise, our focus is on models published for use in developed countries. Health disparities in other countries may require different approaches and warrant further exploration of appropriate theoretical models. Other limitations inherent to metanarrative systematic reviews are also possible, including challenges in identifying sources of evidence and thematically apprising and analysing evidence. Future reviews with expanded search headings, like the new health equity MeSH heading, may identify more publications, including those relevant to the health and public policies domain. The search is also limited in its reference period. Future review may identify new ways of conceptualising paediatric health disparities that were lacking at the time of this review.

\section{CONCLUSIONS}

While the literature on child health disparities is growing, we found that few studies are guided by a multilevel model, and those that are multilevel vary in their constituent parts. A unified conceptual framework specific to child health disparities, which is inclusive of multiple levels and applicable to a diverse range of health-related 
studies, could have broad applicability and set the foundation to integrate existing knowledge of child health disparities and guide future research. It could also provide definitional and conceptual clarity that allows the science to move forward using a common language. Because the framework is multilevel, it can facilitate the combination of clinical, basic and social science research to examine the relationships between policy, the social environment and the physical environment, while guiding data collection and intervention development that address factors at the individual and population levels.

Acknowledgements The authors thank Ms Dawn M Finnie from the Mayo Clinic Robert D. and Patricia E. Kern Center for the Science of Health Care Delivery and Dr Carmen Radecki Breitkopf from the Mayo Clinic Cancer Center for their thoughtful review of the articles that served as the basis for this systematic review. We would also like to thank Mr Larry J Prokop from Mayo Library System, Mayo Clinic, for his significant contribution to our work, particularly the development of the literature search strategy. Finally, the authors thank Ms Heather Morrison and Mr Stephen Smith at NORC at the University of Chicago for their overall guidance on the work undertaken as part of this task order from the National Institute of Child Health and Human Development of the National Institutes of Health.

Contributors JLR reviewed articles, extracted data, critically reviewed and revised the manuscript, and approved the final manuscript as submitted. ZW designed and conceptualised the study, developed the search strategy, designed the data collection instruments, coordinated and supervised data extraction and review, reviewed and revised the manuscript, and approved the final manuscript as submitted. LJFR, MVR and JMG reviewed articles, extracted data, reviewed and revised the manuscript, and approved the final manuscript as submitted. MHM designed and conceptualised the study, developed the search strategy, reviewed and revised the manuscript, and approved the final manuscript as submitted. GBA and JSE reviewed articles, extracted data, critically reviewed the manuscript, and approved the final manuscript as submitted. TJB designed and conceptualised the study, developed the search strategy, carried out the initial analysis, drafted the initial manuscript, and approved the manuscript as submitted. TJB is the guarantor. All authors approved the final manuscript as submitted and agreed to be accountable for all aspects of the work.

\section{Competing interests None declared.}

Patient consent This research did not include data collection from human subjects.

Provenance and peer review Not commissioned; externally peer reviewed.

Data sharing statement Additional data are available by emailing the corresponding author at beebe026@umn.edu.

Open Access This is an Open Access article distributed in accordance with the Creative Commons Attribution Non Commercial (CC BY-NC 4.0) license, which permits others to distribute, remix, adapt, build upon this work non-commercially, and license their derivative works on different terms, provided the original work is properly cited and the use is non-commercial. See: http://creativecommons.org/ licenses/by-nc/4.0/

(c) Article author(s) (or their employer(s) unless otherwise stated in the text of the article) 2017. All rights reserved. No commercial use is permitted unless otherwise expressly granted.

\section{REFERENCES}

1. Institute of Medicine (US) Committee on Understanding and Eliminating Racial and Ethnic Disparities in Health Care. In: Smedley BD, Stith AY, Nelson AR, eds. Unequal Treatment: Confronting Racial and Ethnic Disparities in Health Care. Washington, DC: The National Academies, 2003.

2. U.S Department of Health and Human Services Agency for Healthcare Research and Quality (AHRQ). 2013 National Healthcare Disparities Report. Rockville, MD, 2014.

3. Ayanian JZ, Landon BE, Newhouse JP, et al. Racial and ethnic disparities among enrollees in Medicare Advantage plans. N Engl J Med 2014;371:2288-97.
4. Kamangar F, Dores GM, Anderson WF. Patterns of cancer incidence, mortality, and prevalence across five continents: defining priorities to reduce cancer disparities in different geographic regions of the world. J Clin Oncol 2006;24:2137-50.

5. McWilliams JM, Meara E, Zaslavsky AM, et al. Differences in control of cardiovascular disease and diabetes by race, ethnicity, and education: U.S. trends from 1999 to 2006 and effects of Medicare coverage. Ann Intern Med 2009;150:505-15.

6. U.S Department of Health and Human Services Office of Minority Health. HHS Action Plan to Reduce Racial and Ethnic Disparities: A Nation Free of Disparities in Health and Health Care. Washington, D.C, 2011.

7. United Health Foundation. America's Health Rankings ${ }^{\circledR}$ Annual Report. Minnetonka, MN, 2014.

8. Flores $\mathrm{G}$, Lin H. Trends in racial/ethnic disparities in medical and oral health, access to care, and use of services in US children: has anything changed over the years? Int J Equity Health 2013;12:10.

9. McDaniel M, Paxson C, Waldfogel J. Racial disparities in childhood asthma in the United States: evidence from the National Health Interview Survey, 1997 to 2003. Pediatrics 2006;117:e868-77.

10. Lim JY, Bhatia S, Robison LL, et al. Genomics of racial and ethnic disparities in childhood acute lymphoblastic leukemia. Cancer 2014;120:955-62.

11. Bhatia S. Disparities in cancer outcomes: lessons learned from children with cancer. Pediatr Blood Cancer 2011;56:994-1002.

12. Chan T, Lion KC, Mangione-Smith R. Racial disparities in failureto-rescue among children undergoing congenital heart surgery. $J$ Pediatr 2015;166:e811-4:812-8.

13. Johnson TJ, Weaver MD, Borrero S, et al. Association of race and ethnicity with management of abdominal pain in the emergency department. Pediatrics 2013;132:e851-8.

14. Raphael JL, Beal AC. A review of the evidence for disparities in child vs adult health care: a disparity in disparities. J Natl Med Assoc 2010;102:684-91.

15. U.S Department of Health and Human Services Office of Disease Prevention and Health Promotion. HealthyPeople.gov. https://www. healthypeople.gov/

16. Sallis JF, Owen N, Fisher EB. Ecological models of health behavior. In: Glanz K, Rimer BK K V, eds. Health Behavior and Health Education: Theory, Research, and Practice. 4th ed. San Francisco, CA: Jossey-Bass, 2008:465-485.

17. Stokols D. Translating social ecological theory into guidelines for community health promotion. Am J Health Promot 1996;10:282-98.

18. Warnecke RB, Oh A, Breen N, et al. Approaching health disparities from a population perspective: the National Institutes of Health Centers for Population Health and Health Disparities. Am J Public Health 2008;98:1608-15.

19. Brown P. Race, class, and environmental health: a review and systematization of the literature. Environ Res 1995;69:15-30.

20. Gee GC, Payne-Sturges DC. Environmental health disparities: a framework integrating psychosocial and environmental concepts. Environ Health Perspect 2004;112:1645-53.

21. Subramanian SV, Acevedo-Garcia D, Osypuk TL. Racial residential segregation and geographic heterogeneity in black/white disparity in poor self-rated health in the US: a multilevel statistical analysis. Soc Sci Med 2005;60:1667-79.

22. Adler NE, Rehkopf DH. U.S. disparities in health: descriptions, causes, and mechanisms. Annu Rev Public Health 2008;29:235-52.

23. Dressler WW, Oths KS, Gravlee CC. Race and ethnicity in public health research: Models to explain health disparities. Annu Rev Anthropol 2005;34:231-52.

24. Kuh D, Ben-Shlomo Y, Lynch J, et al. Life course epidemiology. J Epidemiol Community Health 2003;57:778-83.

25. Forrest CB, Simpson L, Clancy C. Child health services research. Challenges and opportunities. JAMA 1997;277:1787-93

26. Stille C, Turchi RM, Antonelli R, et al. The family-centered medical home: specific considerations for child health research and policy. Acad Pediatr 2010;10:211-7.

27. Raphael JL. Observations from the balcony: directions for pediatric health disparities research and policy. J Appl Res Child 2013;4:7.

28. Moher D, Liberati A, Tetzlaff J, et al. Preferred reporting items for systematic reviews and meta-analyses: the PRISMA statement. PLOS Med 2009;6:e1000097.

29. Li D, Wang Z, Shen F, et al. Towards a multi-level framework for supporting systematic review - A pilot study. Paper presented at: International Conference on Bioinformatics and Biomedicine2014.

30. Greenhalgh T, Robert G, Macfarlane F, et al. Storylines of research in diffusion of innovation: a meta-narrative approach to systematic review. Soc Sci Med 2005;61:417-30. 
31. Abu Dabrh AM, Firwana B, Cowl CT, et al. Health assessment of commercial drivers: a meta-narrative systematic review. BMJ Open 2014;4:e003434

32. Shippee ND, Domecq Garces JP, Prutsky Lopez GJ, et al. Patient and service user engagement in research: a systematic review and synthesized framework. Health Expect 2015;18:1151-66.

33. Sobo EJ, Seid M, Reyes Gelhard L. Parent-identified barriers to pediatric health care: a process-oriented model. Health Serv Res 2006;41:148-72.

34. Prado G, Pantin H. Reducing substance use and HIV health disparities among Hispanic youth in the U.S.A.: the Familias Unidas Program of Research. Interv Psicosoc 2011;20:63-73.

35. Mollborn S, Dennis JA. Explaining the early development and health of teen mothers' children. Sociol Forum 2012;27:1010-36.

36. Canino G, Koinis-Mitchell D, Ortega AN, et al. Asthma disparities in the prevalence, morbidity, and treatment of Latino children. Soc Sci Med 2006;63:2926-37.

37. Canino G, McQuaid EL, Alvarez M, et al. Issues and methods in disparities research: the Rhode Island-Puerto Rico asthma center. Pediatr Pulmonol 2009;44:899-908.

38. Canino G, McQuaid EL, Rand CS. Addressing asthma health disparities: a multilevel challenge. J Allergy Clin Immunol 2009:123:1209-17.

39. Chan MF, Ng WI, Van IK. Socioeconomic instability and the availability of health resources: their effects on infant mortality rates in Macau from 1957-2006. J Clin Nurs 2010;19:884-91.

40. Cheng TL, Goodman E, Committee on Pediatric Research. Race, ethnicity, and socioeconomic status in research on child health. Pediatrics 2015;135:e225-e237.

41. Fisher-Owens SA, Isong IA, Soobader MJ, et al. An examination of racial/ethnic disparities in children's oral health in the United States. $J$ Public Health Dent 2013;73:166-74.

42. Flores G, Ngui E. Racial/ethnic disparities and patient safety. Pediatr Clin North Am 2006;53:1197-215.

43. Gao XL, Hsu CY, Xu YC, et al. Behavioral pathways explaining oral health disparity in children. J Dent Res 2010;89:985-90.

44. Graham $\mathrm{H}$, Power $\mathrm{C}$. Childhood disadvantage and health inequalities: a framework for policy based on lifecourse research. Child Care Health Dev 2004;30:671-8.

45. Halfon N, Inkelas M, Wood D. Nonfinancial barriers to care for children and youth. Annu Rev Public Health 1995;16:447-72.

46. Lambert V, Keogh D. Health literacy and its importance for effective communication. Part 1. Nurs Child Young People 2014;26:31-7; quiz 38.

47. Lee H, Hicken MT. Cumulative social risk and racial/ethnic disparities in obesity during the transition to adulthood. $J$ Health Care Poor Underserved 2013:24:907-27.

48. Lindsay S, McDougall C, Menna-Dack D, et al. An ecological approach to understanding barriers to employment for youth with disabilities compared to their typically developing peers: views of youth, employers, and job counselors. Disabil Rehabil 2015;37:701-11.

49. Mohajer N, Earnest J. Widening the aim of health promotion to include the most disadvantaged: vulnerable adolescents and the social determinants of health. Health Educ Res 2010;25:387-94.

50. Park C, Tan X, Patel IB, et al. Racial health disparities among special health care needs children with mental disorders: do medical homes cater to their needs? J Prim Care Community Health 2014;5:253-62.

51. Raphael D. The health of Canada's children. Part II: Health mechanisms and pathways. Paediatr Child Health 2010;15:71-6 https://www.ncbi.nlm.nih.gov/pmc/articles/PMC2865938/.

52. Sidora-Arcoleo K, Feldman JM, Serebrisky D, et al. A multi-factoria model for examining racial and ethnic disparities in acute asthma visits by children. Ann Behav Med 2012;43:15-28.

53. Acevedo-Garcia D, Rosenfeld LE, Hardy E, et al. Future directions in research on institutional and interpersonal discrimination and children's health. Am J Public Health 2013;103:1754-63.

54. Liu J, Probst JC, Martin AB, et al. Disparities in dental insurance coverage and dental care among US children: The National Survey of Children's Health. Pediatrics 2007;119:S12-S21.

55. Sanders-Phillips K, Kliewer W, Tirmazi T, et al. Perceived racial discrimination, drug use, and psychological distress in African American Youth: a pathway to child health disparities. J Soc Issues 2014;70:279-97.

56. Kane DJ, Zotti ME, Rosenberg D. Factors associated with health care access for Mississippi children with special health care needs. Matern Child Health J 2005:9:S23-S31.

57. Li J, Newcomb P. Disparities in childhood asthma hospitalizations: a spatial analysis of contextual effects. Transp. Res. Part D Transp. Environ 2009;14:317-25.
58. Yoo J, Slack KS, Holl JL. The impact of health-promoting behaviors on low-income children's health: a risk and resilience perspective. Health Soc Work 2010;35:133-43.

59. Johnson MJ, Amella EJ. Isolation of lesbian, gay, bisexual and transgender youth: a dimensional concept analysis. J Adv Nurs 2014;70:523-32.

60. Braveman P, Barclay C. Health disparities beginning in childhood: a life-course perspective. Pediatrics 2009;124(Suppl 3):S163-75.

61. Chi DL. Reducing Alaska Native paediatric oral health disparities: a systematic review of oral health interventions and a case study on multilevel strategies to reduce sugar-sweetened beverage intake. Int J Circumpolar Health 2013;72:21066.

62. van der Lucht F, Groothoff J. Social inequalities and health among children aged 10-11 in the Netherlands: causes and consequences. Soc Sci Med 1995;40:1305-11.

63. Satcher D, Rust G. Achieving health equity in America. Ethn Dis 2006;16:S3-8-S3-13.

64. Linton JM, Feudtner C. What accounts for differences or disparities in pediatric palliative and end-of-life care? A systematic review focusing on possible multilevel mechanisms. Pediatrics 2008;122:574-82.

65. Lynam MJ, Loock C, Scott L, et al. Culture, health, and inequalities: new paradigms, new practice imperatives. J Res Nurs 2008;13:138-48

66. Polonijo AN, Carpiano RM. Social inequalities in adolescent human papillomavirus (HPV) vaccination: a test of fundamental cause theory. Soc Sci Med 2013;82:115-25.

67. Fraser MR. Bringing it all together: effective maternal and child health practice as a means to improve public health. Matern Child Health $J$ 2013:17:767-75.

68. Angier H, Gregg J, Gold R, et al. Understanding how low-income families prioritize elements of health care access for their children via the optimal care model. BMC Health Serv Res 2014;14:585.

69. Smith EP, Atkins J, Connell CM. Family, school, and community factors and relationships to racial-ethnic attitudes and academic achievement. Am J Community Psychol 2003;32:159-73.

70. Murphey C, Rew L. Three intervention models for exploring oral health in pregnant minority adolescents. J Spec Pediatr Nurs 2009;14:132-41.

71. Schreier HM, Chen E. Socioeconomic status and the health of youth a multilevel, multidomain approach to conceptualizing pathways. Psychol Bull 2013;139:606-54.

72. Wise PH. The anatomy of a disparity in infant mortality. Annu Rev Public Health 2003;24:341-62.

73. Ochoa ER, Nash C. Community engagement and its impact on child health disparities: building blocks, examples, and resources. Pediatrics 2009;124(Suppl 3):S237-45.

74. Clauss-Ehlers CCC. Promoting ecologic health resilience for minority youth: enhancing health care access through the school health center. Psychol. Sch 2003;40:265-78.

75. Huang KY, Calzada E, Kamboukos D, et al. Applying public health frameworks to advance the promotion of mental health among Asian American children. Asian Am J Psychol 2014;5:145-52.

76. Eiraldi RB, Mazzuca LB, Clarke AT, et al. Service utilization among ethnic minority children with ADHD: a model of help-seeking behavior. Adm Policy Ment Health 2006;33:607-22.

77. Salihu HM, August EM, Alio AP, et al. Community-academic partnerships to reduce black-white disparities in infant mortality in Florida. Prog Community Health Partnersh 2011;5:53-66.

78. Aiken KD, Freed GL, Davis MM. When insurance status is not static: insurance transitions of low-income children and implications for health and health care. Ambul Pediatr. May 2004:4:237-43.

79. Banks J, Marmot M, Oldfield Z, et al. Disease and disadvantage in the United States and in England. JAMA 2006;295:2037-45.

80. Braveman PA, Cubbin C, Egerter S, et al. Socioeconomic disparities in health in the United States: what the patterns tell us. Am J Public Health 2010;100:S186-S196.

81. Farmer MM, Ferraro KF. Are racial disparities in health conditional on socioeconomic status? Soc Sci Med 2005;60:191-204.

82. Karlamangla AS, Merkin SS, Crimmins EM, et al. Socioeconomic and ethnic disparities in cardiovascular risk in the United States, 20012006. Ann Epidemiol 2010;20:617-28.

83. Mackenbach JP, Stirbu I, Roskam AJ, et al. Socioeconomic inequalities in health in 22 European countries. N Engl J Med 2008;358:2468-81.

84. Signorello LB, Cohen SS, Williams DR, et al. Socioeconomic status, race, and mortality: a prospective cohort study. Am J Public Health 2014:104:e98e107.

85. Young JL, Pollack K, Rutkow L. Review of state legislative approaches to eliminating racial and ethnic health disparities, 20022011. Am J Public Health 2015;105(Suppl 3):S388-94. 
86. Juon HS, Evans-Polce RJ, Ensminger M. Early life conditions of overall and cause-specific mortality among inner-city African Americans. Am J Public Health 2014;104:548-54.

87. Pascoe JM, Wood DL, Duffee JH, et al. Mediators and adverse effects of child poverty in the United States. Pediatrics 2016;137:e20160340.

88. Shonkoff JP, Garner AS, Siegel BS, et al. The lifelong effects of early childhood adversity and toxic stress. Pediatrics 2012;129:e232e246:e232-e246.

89. Reifsnider E, Gallagher M, Forgione B. Using ecological models in research on health disparities. J Prof Nurs 2005;21:216-22.

90. Taplin SH, Anhang Price R, Edwards HM, et al. Introduction: understanding and influencing multilevel factors across the Cancer care continuum. J Natl Cancer Inst Monogr 2012;2012:2-10.

91. Bronfenbrenner U. The Ecology of Human Development: Experiments by Nature and Design. Cambridge (MA): Harvard University Press, 1979.

92. Sarche M, Spicer P. Poverty and health disparities for American Indian and Alaska Native children: current knowledge and future prospects. Ann N Y Acad Sci 2008;1136:126-36.

93. U.S Department of Education National Center for Education Statistics Schools and Staffing Survey (SASS). "Public School Data File, "20072008.
94. Huang KY, Cheng S, Theise R. School contexts as social determinants of child health: current practices and implications for future public health practice. Public Health Rep 2013;128:21-8 https://www.ncbi.nIm.nih.gov/pmc/articles/ PMC3945445/.

95. Evans GW, Li D, Whipple SS, et al. Cumulative risk and child development. Psychol Bull 2013;139:1342-96.

96. Halle T, Forry N, Hair E, et al. Disparities in Early Learning and Development: Lessons from the Early Childhood Longitudinal Study Birth Cohort (ECLS-B). Washington, DC, 2009.

97. Umberson D, Montez JK. Social relationships and health: a flashpoint for health policy. J Health Soc Behav 2010;51:S54-S66.

98. Goldhagen J, Mercer R, Webb E, et al. Toward a child rights theory in pediatric bioethics. Perspect Biol Med 2016;58:306-19.

99. National Research Council and Institute of Medicine. Children's Health, the Nation's Wealth: Assessing and Improving Child Health. Committee on Evaluation of Children's Health. Board on Children, Youth, and Families, Division of Behavioral and Social Sciences and Education. Washington, DC: The National Academies Press, 2004.

100. Landrigan PJ. What causes autism? Exploring the environmental contribution. Curr Opin Pediatr 2010;22:219-25. 